\title{
METODE SEMIEMPIRIS UNTUK MENENTUKAN KOMPOSISI ISOTOP URANIUM
}

\author{
Tegas Sutondo \\ Pusat Teknologi Akselerator dan Proses Bahan - BATAN \\ Kotak Pos 6101 ykbb, Yogyakarta 55281
}

\begin{abstract}
ABSTRAK
METODE SEMIEMPIRIS UNTUK MENENTUKAN KOMPOSISI ISOTOP URANIUM. Pada perhitungan desain reaktor nuklir, sering diperlukan beberapa variasi tingkat pengkayaan $U^{235}$. Hal ini akan berpengaruh terhadap komposisi 3 isotop uranium utama yaitu $U^{234}, U^{235}$ dan $U^{238}$ untuk tingkat pengkayaan $U^{235}$ yang diinginkan. Mengingat terbatasnya data komposisi yang tersedia maka perlu dilakukan suatu cara pendekatan, untuk memperkirakan komposisi ke-3 isotop tersebut, sesuai dengan nilai tingkat pengkayaan $U^{235}$ yang diinginkan. Makalah ini menyajikan dasar teori yang digunakan untuk menyusun suatu rumus semi empiris untuk memperkirakan komposisi 3 isotop uranium sebagai fungsi nilai pengkayaan $U^{235}$, yang diperoleh berdasarkan data eksperimen yang tersedia. Berdasarkan data yang tersedia, serta kelangkaan data untuk rentang pengkayaan antara 3,5\% hingga $12 \%$, disimpulkan bahwa untuk isotop $U^{235}$ perlu digunakan 2 persamaan linear yang berbeda yaitu untuk pengkayaan $\leq 3,5 \%$ dan $\geq 3,5 \%$. Untuk isotop $U^{234}$ satu fungsi polinomial orde 4 bisa digunakan secara baik untuk seluruh pengkayaan dalam rentang 0,711 $\%$ hingga $20 \%$, sedangkan untuk pengkayaan yang lebih tinggi (> $20 \%$ ), maka lebih baik digunakan pendekatan persamaan power fitting. Komposisi isotop $U^{238}$ selanjutnya dapat ditentukan dari komposisi isotop $U^{235}$ dan $U^{234}$ untuk pengkayaan $U^{235}$ yang diinginkan.
\end{abstract}

Kata kunci: metode, semiempiris, komposisi, isotop, uranium, pengkayaan.

\section{ABSTRACT}

SEMIEMPIRICAL METHOD TO DETERMINE THE URANIUM ISOTOPIC COMPOSITIONS. In a nuclear reactor design calculation, some variations of $U^{235}$ enrichment are commonly needed. This will affect the isotopic compositions of the 3 main uranium isotopes i.e. $U^{234}, U^{235}$ and $U^{238}$ for the respective enrichment. Due to the limited compositions data available, it is urgent to make an approximate way that can be used to determine the compositions of the 3 isotopes, for the desired enrichments. This paper presents the theoretical background used for constructing a semi empirical formula to estimate the composition of the 3 uranium isotopes as a function of $U^{235}$ enrichment, obtained based on the measurement data available. Based on the available data, and the lack of compositions data within the enrichment range between $3.5 \%$ and around $12 \%$, it is concluded that 2 separate linear equations i.e. for $\leq 3.5 \%$ and $\geq 3.5 \%$ might be needed for $U^{235}$ isotope. For the $U^{234}$ isotope, a polynomial equation of $4^{\text {th }}$ order is well suited to be used for the whole range of enrichment between $0.711 \%$ and $20 \%$, whilst for higher enrichment (> $20 \%$ ), a power function seems to give a better approach. The composition of $U^{238}$ can then be determined from the $U^{235}$ and $U^{234}$ composition at the desired enrichment of $U^{235}$.

Keywords: semiempirical, method, composition, isotope, uranium, enrichment.

\section{PENDAHULUAN}

ranium adalah material jenis logam dengan densitas tinggi yaitu $18.9 \mathrm{~g} / \mathrm{cm}^{3}$. Secara alamiah, uranium terdiri dari 3 isotop utama, yaitu $\mathrm{U}^{238}, \mathrm{U}^{235}$, and $\mathrm{U}^{234}$ yang ketiganya bersifat radioaktif. $\mathrm{U}^{238}$ dan $\mathrm{U}^{235}$ adalah induk nuklida dari 2 deret peluruhan yang terpisah, sedang $U^{234}$ adalah hasil peluruhan dari $U^{238}$. Dari ketiga isotop tersebut, $U^{238}$ sebagai bagian terbesar, sedang $U^{234}$ paling kecil ${ }^{(1,2)}$, yang dalam beberapa hal, keberadaannya dapat diabaikan.

Pada kegiatan yang terkait dengan perhitungan desain teras reaktor, yang membutuhkan tingkat ketelitian yang tinggi, terutama untuk bahan bakar dengan tingkat pengkayaan yang relatif tinggi, maka diperlukan informasi mengenai data komposisi dari ke-3 isotop tersebut. Mengingat informasi yang tersedia mengenai data komposisi isotop tersebut sebagai fungsi tingkat pengkayaan sangat terbatas, maka diperlukan suatu pendekatan untuk dapat memperkirakan komposisi isotop tersebut pada tingkat pengkayaan yang diinginkan.

Data komposisi isotop yang tersedia pada umumnya diperoleh berdasarkan pada hasil pengukuran menggunakan beberapa metode, seperti metode Quadrupole Inductively Coupled Plasma-Mass Spectrometry, Thermal Ionization Mass Spectrometry ${ }^{(4,5,6)}$, atau metode spektrometri gamma ${ }^{(7)}$. Penggunaan metode tersebut, 
selain memerlukan peralatan khusus juga memerlukan banyak waktu, tenaga dan biaya, sehingga untuk perhitungan neutronik yang memerlukan banyak variasi tingkat pengkayaan, metode tersebut menjadi tidak praktis. Atas dasar pertimbangan tersebut, maka perlu dilakukan suatu pendekatan, yang dapat digunakan untuk memperkirakan komposisi ke-3 isotop uranium tersebut pada sembarang tingkat pengkayaan yang diinginkan secara praktis, namun dengan tingkat ketelitian yang cukup baik.

Makalah ini memperkenalkan suatu metode semi empiris untuk menentukan komposisi ke-3 isotop tersebut, berdasarkan data komposisi isotop uranium pada beberapa tingkat pengkayaan yang tersedia ${ }^{(1,2,3)}$ yang dapat digunakan sebagai pendekatan, khususnya dalam perhitungan neutronik reaktor nuklir yang memerlukan beberapa variasi tingkat pengkayaan yang belum tersedia.

\section{DASAR TEORI}

Komposisi nuklida atau isotop dari suatu bahan dapat dinyatakan dalam beberapa parameter, antara lain:

1. Parameter fraksi atom $\left(\mathrm{f}_{\mathrm{i}}\right)$ yang menyatakan rasio jumlah nuklida atau isotop $\left(\mathrm{n}_{\mathrm{i}}\right)$ terhadap jumlah total kandungan yang ada persatuan volume atau per satuan massa. Berdasarkan definisi tersebut, maka $f_{i}$ dapat dinyatakan sebagai rasio rapat atom atau isotop $\left(\mathrm{N}_{\mathrm{i}}\right)$ terhadap total rapat atom dari seluruh nuklida atau isotop yang terkandung pada suatu bahan. Secara matematis fraksi atom dapat dinyatakan berdasarkan persamaan berikut:

$$
\mathrm{f}_{\mathrm{i}}=\frac{\mathrm{n}_{\mathrm{i}} / \mathrm{V}}{\sum_{\mathrm{i}} \mathrm{n}_{\mathrm{i}} / \mathrm{V}}=\frac{\mathrm{N}_{\mathrm{i}}}{\sum_{\mathrm{i}} \mathrm{N}_{\mathrm{i}}}
$$

dengan

$V=$ volume $\left(\mathrm{cm}^{3}\right)$ dan

$N_{i}=$ rapat atom dari masing-masing nuklida atau isotop $\left(\right.$ atom $\left./ \mathrm{cm}^{3}\right)$.

2. Parameter fraksi berat $\left(\mathrm{w}_{\mathrm{i}}\right)$ yang menyatakan rasio berat atau massa nuklida atau isotop $\left(\mathrm{g}_{\mathrm{i}}\right)$ terhadap berat total nuklida yang ada di dalam bahan per satuan volume atau per satuan massa. Berdasarkan definisi tersebut, maka $w_{i}$ dapat dinyatakan sebagai rasio rapat massa dari suatu nuklida atau isotop $\left(\rho_{i}\right)$ terhadap total rapat massa dari seluruh nuklida atau isotop yang terkandung pada suatu bahan. Secara matematis fraksi atom dapat dinyatakan berdasarkan persamaan berikut:

$$
\mathrm{w}_{\mathrm{i}}=\frac{\mathrm{g}_{\mathrm{i}} / \mathrm{V}}{\sum_{\mathrm{i}} \mathrm{g}_{\mathrm{i}} / \mathrm{V}}=\frac{\rho_{\mathrm{i}}}{\sum_{\mathrm{i}} \rho_{\mathrm{i}}}=\frac{\mathrm{f}_{\mathrm{i}} \mathrm{A}_{\mathrm{i}}}{\sum_{\mathrm{i}} \mathrm{f}_{\mathrm{i}} \mathrm{A}_{\mathrm{i}}}
$$

dengan

$g_{i}=$ berat dari masing-masing nuklida atau isotop (gram)

$\rho_{i}=$ densitas dari masing-masing nuklida atau isotop $\left(\mathrm{gram} / \mathrm{cm}^{3}\right)$

$f_{i}=$ fraksi atom dari masing-masing nuklida atau isotop

$A_{i}=$ massa atom dari masing-masing nuklida atau isotop

Pada uranium alam kelimpahan $U^{235}$ sebagai satu satunya isotop dengan kategori bahan fisil (fissile material) yang terdapat secara alamiah relatif kecil yaitu sekitar $0,711 \%$ berat. Untuk itu, perlu dilakukan proses pengkayaan (enrichment) untuk meningkatkan kadarnya sehingga dapat digunakan sebagai bahan bakar reaktor sesuai dengan siklus pemuatan yang diinginkan. Tingkat atau nilai pengkayaan dari $U^{235}(\varepsilon)$ menyatakan fraksi berat dari $U^{235}$ terhadap total fraksi berat dari masing-masing isotop uranium. Dengan demikian pada hakekatnya nilai pengkayaan $\varepsilon$ sama dengan nilai fraksi berat dari $U^{235}$ sebagaimana dinyatakan pada persamaan (2). Tabel 1 memuat data komposisi isotop uranium alam ${ }^{(1)}$

Secara teoritis apabila kadar isotop $\mathrm{U}^{235}$ ditingkatkan, maka kadar isotop $\mathrm{U}^{234}$ juga akan mengalami peningkatan dengan laju peningkatan yang lebih tinggi dari $U^{235}$, yang disebabkan oleh massa isotop $U^{234}$ yang sedikit lebih kecil. Namun demikian mengingat proses pengkayaan menyangkut banyak aspek keteknikan (engineering), maka tidak tersedia formula matematis yang dapat menyatakan korelasi secara eksak antara massa atom dengan laju peningkatan komposisi dari ke-2 isotop tersebut sebagai fungsi tingkat pengkayaan. 
Mengingat keterbatasan data komposisi isotop uranium yang tersedia, maka perlu digunakan pendekatan secara semiempiris berdasarkan data pengukuran eksperimen yang tersedia, untuk memperkirakan komposisi dari ke-2 isotop tersebut sebagai fungsi pengkayaan.

Tabel 1. Komposisi isotop uranium alam ${ }^{(1)}$

\begin{tabular}{|l|c|c|c|c|}
\hline \multicolumn{5}{|c|}{ Komposisi Isotop Uranium Alam } \\
\hline Prosentase & $\begin{array}{c}\mathbf{U}^{234} \\
(\mathbf{A}=\mathbf{2 3 4}, \mathbf{0 4 1})\end{array}$ & $\begin{array}{c}\mathbf{U}^{235} \\
(\mathbf{A}=\mathbf{2 3 5}, \mathbf{0 4 3 9})\end{array}$ & $\begin{array}{c}\mathbf{U}^{238} \\
(\mathbf{A}=\mathbf{2 3 8}, \mathbf{0 5 0 8})\end{array}$ & Total \\
\hline Atom (\%) & $0.0054 \%$ & $0.72 \%$ & $99.275 \%$ & $100 \%$ \\
\hline Berat (\%) & $0.0053 \%$ & $0.711 \%$ & $99.284 \%$ & $100 \%$ \\
\hline Aktivitas & $48.9 \%$ & $2.2 \%$ & $48.9 \%$ & $100 \%$ \\
\hline $\begin{array}{l}\text { Aktivitas dalam 1 g } \\
\text { Ualam }^{\text {ala }}\end{array}$ & $12356 \mathrm{~Bq}$ & $568 \mathrm{~Bq}$ & $12356 \mathrm{~Bq}$ & $25280 \mathrm{~Bq}$ \\
\hline
\end{tabular}

\section{METODOLOGI}

\section{Gain Factor}

Seperti telah diuraikan pada bab sebelumnya, bahwa bila kadar $U^{235}$ ditingkatkan maka kadar $U^{234}$ juga akan mengalami peningkatan dengan laju peningkatan yang lebih tinggi, yang disebabkan oleh massa isotop $U^{234}$ yang sedikit lebih kecil. Untuk mengetahui laju peningkatan dari ke-2 isotop tersebut, pada makalah ini diperkenalkan suatu parameter yang disebut dengan gain factor $G(\varepsilon)$ yang menyatakan faktor peningkatan dari kedua isotop tersebut sebagai fungsi pengkayaan yang didefinisikan sebagai rasio nilai komposisi atau fraksi atom (f) pada tingkat pengkayaan tertentu $(\varepsilon)$ terhadap nilai komposisi awalnya (uranium alam). Berdasarkan definisi tersebut, maka gain factor untuk $\mathrm{U}^{235}$ dan $\mathrm{U}^{234}$ dinyatakan sebagai berikut:

$$
\begin{aligned}
& \mathrm{G}^{235}(\varepsilon)=\mathrm{f}^{235}(\varepsilon) / f_{0}^{235} \\
& \mathrm{G}^{234}(\varepsilon)=\mathrm{f}^{234}(\varepsilon) / \mathrm{f}_{0}^{234}
\end{aligned}
$$

dengan $f_{0}=$ fraksi masing-masing isotop pada kondisi alamiah (uranium alam)

Tabel 2 menyajikan data komposisi dari ke-3 isotop uranium untuk beberapa tingkat pengkayaan $U^{235}[1,5]$, dan selanjutnya dapat ditentukan besarnya gain factor $\mathrm{G}$ untuk kedua isotop $\mathrm{U}^{235}$ dan $\mathrm{U}^{234}$ berdasarkan persamaan (3). Dari nilai $G$ tersebut selanjutnya dilakukan fitting untuk mendapatkan rumus semiempiris yang dapat digunakan untuk sembarang tingkat pengkayaan $U^{235}$ sehingga dapat ditentukan nilai fraksi atom berdasarkan persamaan (3) atau fraksi berat berdasarkan persamaan (2).

Tabel 2. Komposisi isotop uranium pada beberapa tingkat pengkayaan

\begin{tabular}{|c|c|c|c|}
\hline \multirow{2}{*}{$\begin{array}{c}\text { Pengkayaan } U^{235} \\
(\% \text { berat })\end{array}$} & \multicolumn{3}{|c|}{ Fraksi Atom } \\
\cline { 2 - 4 } & $\begin{array}{c}U^{235} \\
(\mathrm{~A}=235,0439)\end{array}$ & $\begin{array}{c}\mathrm{U}^{234} \\
(\mathrm{~A}=234,041)\end{array}$ & $\begin{array}{c}\mathrm{U}^{238} \\
(\mathrm{~A}=238,0508)\end{array}$ \\
\hline $0,711 \%$ & $7,2000 \mathrm{E}-03$ & $5,5000 \mathrm{E}-05$ & $9,9275 \mathrm{E}-01$ \\
$3,500 \%$ & $3,5432 \mathrm{E}-02$ & $2,9321 \mathrm{E}-04$ & $9,6428 \mathrm{E}-01$ \\
$12,320 \%$ & $1,2320 \mathrm{E}-01$ & $1,1800 \mathrm{E}-03$ & $8,7562 \mathrm{E}-01$ \\
$14,110 \%$ & $1,4264 \mathrm{E}-01$ & $1,3600 \mathrm{E}-03$ & $8,5600 \mathrm{E}-01$ \\
$16,010 \%$ & $1,6011 \mathrm{E}-01$ & $1,5500 \mathrm{E}-03$ & $8,3834 \mathrm{E}-01$ \\
\hline
\end{tabular}




\section{HASIL DAN PEMBAHASAN}

Tabel 3 menyajikan perbandingan antara data dan hasil fitting nilai gain factor untuk $U^{235}$ dengan menggunakan pendekatan fungsi linear untuk seluruh tingkat pengkayaan (linear fitt-1) dan 2 fungsi linear dengan 2 rentang tingkat pengkayaan yang berbeda (linear fitt-2) yaitu untuk pengkayaan $\leq 3,5 \%$ dan untuk $\geq 3,5 \%$.

Tabel 3. Perbandingan data dan hasil fitting gain factor $\mathrm{U}^{235}$

\begin{tabular}{|c|c|c|c|c|c|}
\hline \multirow{2}{*}{$\begin{array}{l}\text { Pengkayaan } \mathrm{U}^{235} \\
\text { (\% berat) }\end{array}$} & \multicolumn{3}{|c|}{ Rain factor $\mathrm{U}^{235}[\mathrm{f}(\varepsilon) / \mathrm{f}(\mathrm{nat})]$} & \multicolumn{2}{c|}{ Perbedaan relatif $(\%)$} \\
\cline { 2 - 6 } & Data & Linear fitt-1 & Linear fitt-2 & Linear fitt-1 & Linear fitt-2 \\
\hline 0,711 & 1,000 & 1,018 & 1,000 & 1,817 & 0,005 \\
3,500 & 4,921 & 4,901 & 4,921 & 0,418 & 0,002 \\
12,320 & 17,111 & 17,178 & 17,178 & 0,390 & 0,390 \\
14,110 & 1,811 & 19,670 & 19,670 & 0,317 & 0,317 \\
16,010 & 22,238 & 22,314 & 22,314 & 0,345 & 0,345 \\
\hline
\end{tabular}

Terlihat bahwa pendekatan linear fitt-1 memberikan perbedaan relatif terbesar sekitar 1,8\% pada kondisi alamiah, sedang untuk tingkat pengkayaan yang $\geq 3,5 \%$ menunjukkan hasil yang cukup baik. Hal ini bisa disebabkan rentang nilai pengkayaan yang agak lebar antara 3,5 \% dan $12,32 \%$. Untuk pengkayaan $\geq 3,5 \%$ hasilnya cukup baik, dengan perbedaan relatif kurang dari $1 \%$. Dengan demikian, khusus untuk pengkayaan $\leq 3,5$ dilakukan fitting secara terpisah menggunakan 2 titik data $(0,711 \%$ dan $3,5 \%)$ sehingga hasilnya sangat baik. Persamaan (4) adalah rumus gain faktor untuk $U^{235}$ untuk 2 rentang pengkayaan tersebut.

$$
\begin{aligned}
& G^{235}(\varepsilon)=140,59 \varepsilon+0,0005 ; \rightarrow 0,711 \% \text { berat } \leq \varepsilon \leq 3,5 \% \text { berat } \\
& G^{235}(\varepsilon)=139,2 \varepsilon+0,0285 ; \rightarrow \varepsilon \geq 3,5 \% \text { berat }
\end{aligned}
$$

Tabel 4 menyajikan perbandingan antara data dan hasil fitting nilai gain factor untuk $\mathrm{U}^{234}$ dengan menggunakan 3 pendekatan yaitu fungsi linear, fungsi pangkat (power fitting) dan fungsi polinomial orde 4 (polynomial fitting).

Tabel 4. Perbandingan data dan hasil fitting gain factor $\mathrm{U}^{234}$

\begin{tabular}{|c|r|r|r|r|r|r|r|}
\hline Pengkayaan & \multicolumn{3}{|c|}{ Rain factor $\mathrm{U}^{235}[\mathrm{f}(\varepsilon) / f($ nat $)]$} & \multicolumn{3}{|c|}{ Perbedaan relatif (\%) } \\
\cline { 2 - 8 } $\mathrm{U}^{235}$ (\% berat) & \multicolumn{1}{|c|}{ Data } & Linear fitt & Power fitt & Polinom fitt & Linear fitt & Power fitt & \multicolumn{1}{c|}{ Polin fitt } \\
\hline 0,711 & 1,000 & 0,6968 & 0,9874 & 1,0000 & 30,322 & 1,263 & 0,003 \\
3,500 & 5,3311 & 5,6936 & 5,4866 & 5,3312 & 6,801 & 2,918 & 0,002 \\
12,320 & 21,4546 & 21,4955 & 21,2513 & 21,4551 & 0,190 & 0,948 & 0,002 \\
14,110 & 24,7271 & 24,7025 & 24,5912 & 24,7277 & 0,100 & 0,550 & 0,002 \\
16,010 & 28,1820 & 28,1065 & 28,1717 & 28,1287 & 0,268 & 0,037 & 0,002 \\
\hline
\end{tabular}

Dari Tabel 4 terlihat bahwa pendekatan fungsi linear memberikan perbedaan relatif terbesar untuk pengkayaan $\leq 3,5 \%$ yaitu sekitar 6,8 hingga 30,3\% sedang fungsi pangkat tampak memberikan hasil yang lebih baik, dengan perbedaan relatif terbesar sekitar 2,9\% pada pengkayaan 3,5\% dan nilai perbedaan tersebut semakin kecil dengan meningkatnya pengkayaan. Dari hasil tersebut, terlihat bahwa pendekatan power fitting lebih sesuai untuk pengkayaan di atas $12 \%$ berat dengan perbedaan relatif kurang dari $1 \%$.

Untuk pendekatan fungsi polinomial orde 4 menunjukkan hasil yang jauh lebih baik, untuk seluruh rentang tingkat pengkayaan yang ada dengan perbedaan relatif terbesar sekitar $0,003 \%$. Sekalipun demikian dari Gambar 1, memperlihatkan adanya hasil estimasi yang semakin besar dan dengan kecenderungan penyimpangan yang semakin besar (overestimate) terhadap nilai yang semestinya, untuk tingkat pengkayaan yang lebih tinggi. Terlihat bahwa pada tingkat pengkayaan sekitar $23 \%$, hasilnya mulai menyimpang terhadap hasil pendekatan menggunakan fungsi pangkat dan perbedaannya semakin besar dengan naiknya pengkayaan.

Dari perilaku ketiga fungsi tersebut, maka dapat disimpulkan bahwa pendekatan polinomial orde 4 sangat cocok untuk tingkat pengkayaan rendah hingga sekitar $20 \%$, sedang untuk tingkat pengkayaan di atas $20 \%$, 
pendekatan fungsi pangkat (power fitting) memberikan hasil yang lebih baik. Persamaan (5) adalah rumus gain faktor untuk $\mathrm{U}^{234}$ dengan menggunakan pendekatan polynomial dan power fitting.

$$
\begin{array}{ll}
G^{234}(\varepsilon)=10162 \varepsilon^{4}-4881,9 \varepsilon^{3}+821,62 \varepsilon^{2}+127,59 \varepsilon+0,0531 & ; \rightarrow 0,711 \% \leq \varepsilon \leq 20 \% \text { berat } \\
G^{234}(\varepsilon)=202,25 \varepsilon^{1,076} & ; \rightarrow \quad \varepsilon \geq 12 \% \text { berat }
\end{array}
$$

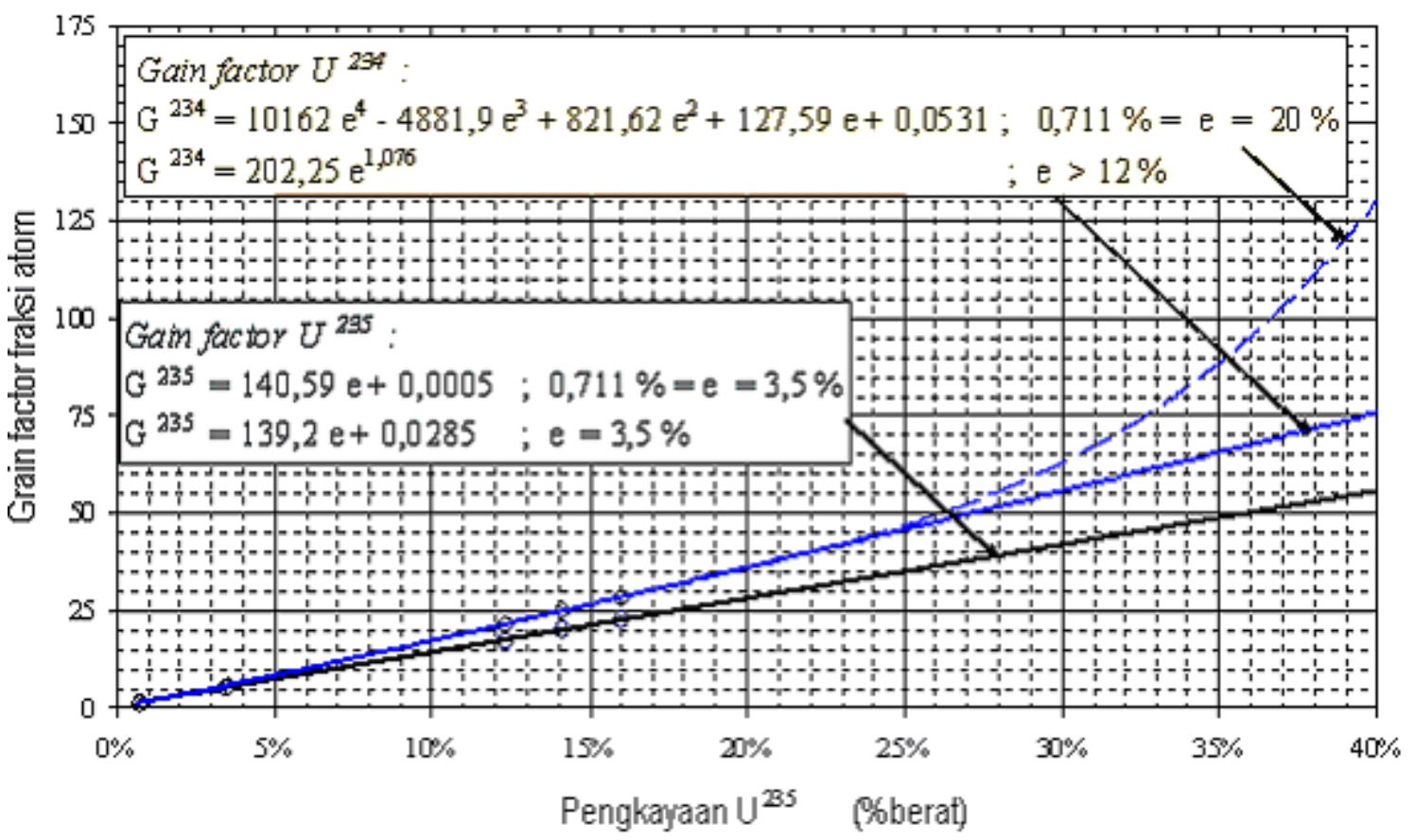

Gambar 1. Persamaan gain factor $\mathrm{U}^{235}$ dan $\mathrm{U}^{234}$ sebagai fungsi pengkayaan

Selanjutnya berdasarkan rumus gain factor (4) dan (5) serta persamaan (3) maka dapat ditentukan rumus empiris untuk fraksi atom $U^{235}$ dan $U^{234}$ sebagai fungsi pengkayaan dan hasilnya seperti ditunjukkan pada persamaan (6) dan (7).

$$
\begin{gathered}
f^{235}(\varepsilon)=1,01225 \varepsilon+3,6 \times 10^{-6} ; \rightarrow 0,711 \% \text { berat } \leq \varepsilon \leq 3,5 \% \text { berat } \\
f^{235}(\varepsilon)=1,00224 \varepsilon+2,0521 \times 10^{-4} ; \rightarrow \varepsilon \geq 3,5 \% \text { berat } \\
f^{234}(\varepsilon)=0,55891 \varepsilon^{4}-0,26851 \varepsilon^{3}+4,5189 \times 10^{-2} \varepsilon^{2}+7,0175 \times 10^{-3} \varepsilon+2,921 \times 10^{-6} ; \\
\rightarrow 0,711 \% \text { berat } \leq \varepsilon \leq 20 \% \text { berat } \\
f^{235}(\varepsilon)=1,1124 \times 10^{-2} \varepsilon^{1,076} ; \rightarrow \varepsilon \geq 12 \% \text { berat }
\end{gathered}
$$

Fraksi atom dari $\bigcup^{238}$ selanjutnya dapat ditentukan berdasarkan persamaan (8)

$$
f^{238}(\varepsilon)=1-\left[f^{234}(\varepsilon)+f^{235}(\varepsilon)\right]
$$

Berdasarkan persamaan (6), (7) dan persamaan (2) selanjutnya dapat ditentukan besarnya fraksi berat dari ke-3 isotop tersebut. Tabel 5 menyajikan hasil perhitungan komposisi dari ke-3 isotop tersebut berdasarkan rumus semiempiris di atas untuk beberapa nilai pengkayaan $\mathrm{U}^{235}$. 
Tabel 5. Komposisi isotop uranium untuk beberapa nilai pengkayaan $\mathrm{U}^{235}$ hingga $20 \%$

\begin{tabular}{|c|c|c|c|c|c|c|}
\hline \multirow{2}{*}{\begin{tabular}{c} 
Pengkayaan $\begin{array}{l}235 \\
\text { (\%berat) }\end{array}$ \\
\cline { 2 - 7 }
\end{tabular}} & $\mathrm{U}^{234}$ & $\mathrm{U}^{235}$ & $\mathrm{U}^{238}$ & $\mathrm{U}^{234}$ & $\mathrm{U}^{235}$ & $\mathrm{U}^{238}$ \\
\hline 0.711 & $5.500 \mathrm{E}-05$ & $7.200 \mathrm{E}-03$ & $9.927 \mathrm{E}-01$ & $5.408 \mathrm{E}-05$ & $7.110 \mathrm{E}-03$ & $9.928 \mathrm{E}-01$ \\
2.0 & $1.593 \mathrm{E}-04$ & $2.025 \mathrm{E}-02$ & $9.796 \mathrm{E}-01$ & $1.566 \mathrm{E}-04$ & $2.000 \mathrm{E}-02$ & $9.798 \mathrm{E}-01$ \\
3.5 & $2.932 \mathrm{E}-04$ & $3.543 \mathrm{E}-02$ & $9.643 \mathrm{E}-01$ & $2.884 \mathrm{E}-04$ & $3.500 \mathrm{E}-02$ & $9.647 \mathrm{E}-01$ \\
5.0 & $4.367 \mathrm{E}-04$ & $5.032 \mathrm{E}-02$ & $9.492 \mathrm{E}-01$ & $4.296 \mathrm{E}-04$ & $4.971 \mathrm{E}-02$ & $9.499 \mathrm{E}-01$ \\
7.0 & $6.369 \mathrm{E}-04$ & $7.036 \mathrm{E}-02$ & $9.290 \mathrm{E}-01$ & $6.267 \mathrm{E}-04$ & $6.954 \mathrm{E}-02$ & $9.298 \mathrm{E}-01$ \\
9.0 & $8.415 \mathrm{E}-04$ & $9.041 \mathrm{E}-02$ & $9.088 \mathrm{E}-01$ & $8.282 \mathrm{E}-04$ & $8.937 \mathrm{E}-02$ & $9.098 \mathrm{E}-01$ \\
10.0 & $9.439 \mathrm{E}-04$ & $1.004 \mathrm{E}-01$ & $8.986 \mathrm{E}-01$ & $9.292 \mathrm{E}-04$ & $9.929 \mathrm{E}-02$ & $8.998 \mathrm{E}-01$ \\
12.0 & $1.148 \mathrm{E}-03$ & $1.205 \mathrm{E}-01$ & $8.784 \mathrm{E}-01$ & $1.130 \mathrm{E}-03$ & $1.191 \mathrm{E}-01$ & $8.797 \mathrm{E}-01$ \\
14.0 & $1.349 \mathrm{E}-03$ & $1.405 \mathrm{E}-01$ & $8.581 \mathrm{E}-01$ & $1.329 \mathrm{E}-03$ & $1.390 \mathrm{E}-01$ & $8.597 \mathrm{E}-01$ \\
15.0 & $1.449 \mathrm{E}-03$ & $1.505 \mathrm{E}-01$ & $8.480 \mathrm{E}-01$ & $1.427 \mathrm{E}-03$ & $1.489 \mathrm{E}-01$ & $8.496 \mathrm{E}-01$ \\
16.5 & $1.549 \mathrm{E}-03$ & $1.606 \mathrm{E}-01$ & $8.379 \mathrm{E}-01$ & $1.576 \mathrm{E}-03$ & $1.638 \mathrm{E}-01$ & $8.346 \mathrm{E}-01$ \\
18.0 & $1.751 \mathrm{E}-03$ & $1.806 \mathrm{E}-01$ & $8.176 \mathrm{E}-01$ & $1.725 \mathrm{E}-03$ & $1.787 \mathrm{E}-01$ & $8.195 \mathrm{E}-01$ \\
20.0 & $1.960 \mathrm{E}-03$ & $2.007 \mathrm{E}-01$ & $7.974 \mathrm{E}-01$ & $1.932 \mathrm{E}-03$ & $1.986 \mathrm{E}-01$ & $7.994 \mathrm{E}-01$ \\
\hline
\end{tabular}

\section{KESIMPULAN}

Telah diuraikan dasar teori dari suatu rumus semi empiris untuk menentukan komposisi 3 isotop uranium sebagai fungsi nilai pengkayaan $\mathrm{U}^{235}$, yang diperoleh berdasarkan data komposisi dari ke-3 isotop tersebut untuk beberapa nilai pengkayaan $\mathrm{U}^{235}$ yang tersedia. Parameter gain factor dari $\mathrm{U}^{235}$ dan $\mathrm{U}^{234}$ telah diperkenalkan dalam metode ini, yang menyatakan rasio fraksi atom dari ke-2 isotop tersebut untuk sembarang pengkayaan terhadap nilai fraksi atom pada kondisi alamiah (uranium alam). Berdasarkan hasil fitting yang terbaik untuk data pengkayaan yang tersedia, maka diperoleh rumus gain factor, dari isotop $\mathrm{U}^{235}$ dan $\mathrm{U}^{234}$ sebagai fungsi pengkayaan, yang selanjutnya dapat digunakan untuk menentukan rumus komposisi dari ke-3 isotop uranium. Disimpulkan bahwa dengan keterbatasan data komposisi untuk rentang pengkayaan antara 3,5\% dan sekitar 12 $\%$, maka untuk isotop $\mathrm{U}^{235}$ perlu digunakan 2 persamaan linear yang berbeda yaitu untuk pengkayaan $\leq 3,5 \%$ dan $\geq 3,5 \%$. Sedang untuk isotop $\mathrm{U}^{234}$ pendekatan fungsi polynomial orde 4 dapat digunakan untuk seluruh pengkayaan dalam rentang $0,711 \%$ hingga $20 \%$, sedangkan untuk pengkayaan yang lebih tinggi (> $20 \%$ ), maka lebih baik digunakan pendekatan persamaan power fitting. Metode ini diharapkan dapat digunakan sebagai pendekatan untuk memperkirakan komposisi isotop uranium khususnya dalam perhitungan neutronik reaktor nuklir.

\section{DAFTAR PUSTAKA}

1. http://www.wise-uranium.org/rup.html, Uranium Radiation Properties

2. http://physics.nist.gov/cgi-bin/Compositions/stand_alone.pl?ele=U, Atomic Weights and Isotopic Compositions for Uranium

3. JUDITH F. BRIESMEISTER, MCNP - A General Montecarlo N-Particle Transport Code version 4B. 
4. http://webstore.ansi.org/ansidocstore/product.asp?sku=ASTM+C14740(2006)e1,ASTM C1474-00(2006) e1, Standard Test Method for Analysis of Isotopic Composition of Uranium in Nuclear-Grade Fuel Material by Quadrupole Inductively Coupled Plasma-Mass Spectrometry

5. http://www.astm.org/cgi.bin/SoftCart.exe/DATABASE.CART/ ,C1625-05, Standard Test Method for Uranium and Plutonium Concentrations and Isotopic Abundances by Thermal Ionization Mass Spectrometry

6. SUSAN E. HOWE, CHRISTINE M. DAVIDSON, and MARTIN MCCARTNEY, Determination of uranium concentration and isotopic composition by means of ICP-MS in sequential extracts of sediment from the vicinity of a uranium enrichment plant, J. Anal. At. Spectrom., 2002

7. http://engineers.ihs.com/document/abstract/, ASTM C 1030 Standard Test Method for Determination of Plutonium Isotopic Composition by Gamma-Ray Spectrometry 